\title{
A study of the efficacy and safety of the balloon tamponade in the management of atonic post-partum hemorrhage
}

\author{
Aruna Kumar, Khushboo Kachchhap*, Shubha Shrivastava
}

Department of Obstetrics and Gynecology, Gandhi Medical College and Associated Sultania Zanana Hospital, Bhopal, Madhya Pradesh, India

Received: 22 January 2020

Accepted: 28 February 2020

*Correspondence:

Dr. Khushboo Kachchhap,

E-mail: khushbookachchhap14@gmail.com

Copyright: (C) the author(s), publisher and licensee Medip Academy. This is an open-access article distributed under the terms of the Creative Commons Attribution Non-Commercial License, which permits unrestricted non-commercial use, distribution, and reproduction in any medium, provided the original work is properly cited.

\section{ABSTRACT}

Background: The most common cause of post-partum hemorrhage $(\mathrm{PPH})$ is uterine atony. Treatment for atony follows a well-defined stepwise approach, including drugs and mechanical interventions followed by surgery as a last resort. Early use of intrauterine balloon tamponade is a way of limiting ongoing uterine blood loss while initiating other measures and can be readily implemented by providers with minimal training.

Methods: This prospective interventional study was conducted in 112 consecutive patients attended department of obstetrics and gynecology, Gandhi Medical College and Associated Sultania Zanana Hospital, Bhopal, Madhya Pradesh, India, in one year of study period.

Results: In this study most of the patients had gestational age $>37$ weeks [83 (74.1\%)]. Most of the patients in the study had vaginal delivery [64 (57.1\%)]. In 84 (75\%) patients Bakri balloon was used followed by Burke balloon in $17(15.2 \%)$ patients, condom catheter in $7(6.2 \%)$ patients and CG balloon in $4(3.6 \%)$ patients. Different types of balloons were used according to availability of balloon at the time of management. Most of the patients [71 (63.3\%)] had trans-vaginal route of balloon placement and $41(36.7 \%)$ patients underwent trans-abdominal balloon placement. Most of the patients 69 (61.65\%), responded to tamponing within 20 minutes of balloon placement while 9 patients had negative tamponade and continued to bleed. Bakri balloon tamponade was most commonly used in $84(75.0 \%)$ patients. CG balloon and condom catheter were used only in $4(3.6 \%)$ and $7(6.3 \%)$ patients respectively. Tamponading was effective and successful in 103 (92\%) patients.

Conclusions: PPH is still a leading but preventable cause of maternal morbidity and mortality. In the majority of cases, relatively simple methods are used to avert a disaster, although these are not always employed. Uterine tamponade using intrauterine balloons appears to be an effective tool in the management of PPH.

Keywords: Bakri balloon, Burke balloon, Lower segment caesarian section, Post-partum hemorrhage, Uterine atony, Uterine balloon tamponade

\section{INTRODUCTION}

Postpartum haemorrhage (PPH) is a leading cause of maternal mortality and morbidity worldwide. According to WHO, PPH occurs in $2-6 \%$ women after birth and accounts for $25 \%$ of all maternal deaths. ${ }^{1}$ Though it is at declining trend it still remains the major cause of maternal mortality. It contributes to 115,000 maternal deaths a year with $99 \%$ of these deaths occurring in lowresource settings. In India maternal deaths due to $\mathrm{PPH}$ is as high as $30 \%$. Maternal mortality remains high in lowand middle-income countries despite a 43\% drop-in maternal death rates worldwide since $1990 .^{2}$

$\mathrm{PPH}$ is defined as vaginal bleeding in excess of $500 \mathrm{ml}$ within 24 hours of delivery, PPH is dangerous and life- 
threatening. ${ }^{3}$ It can also lead to long-lasting health effects, including severe anemia, Sheehans syndrome and its sequelae. The most common cause of PPH is uterine atony. Treatment for atony follows a well-defined stepwise approach, including drugs and mechanical interventions followed by surgery as a last resort. In 2012, the World Health Organization (WHO) recommended use of the uterine balloon tamponade (UBT) for treatment of uterine atony when uterotonic drugs are ineffective or unavailable. UBT was introduced in 1991, is one of the most popular non-surgical interventions, due to its relative simplicity and ease of use.

The principle of balloon tamponade therapy is to fill the uterine cavity with pressure and thereby closing the bleeding sinuses. The increased intrauterine pressure becomes superior to capillary blood vessels pressure which arrests bleeding. It also exerts inward to outward pressure that is greater than systemic arterial pressure thus bleeding is arrested. The purpose of this study was to evaluate the efficacy and safety of intrauterine balloon tamponade in management of atonic PPH and to study the outcome of patients in terms of maternal morbidity and mortality.

\section{METHODS}

The present study was conducted in the department of obstetrics and gynecology, Gandhi Medical College and Associated Sultania Zanana Hospital, Bhopal, Madhya Pradesh, India. The study was done for the duration of 1 year.

Hospital based prospective interventional study conducted from $1^{\text {st }}$ March 2017 to $31^{\text {st }}$ October 2017 and $15^{\text {th }}$ May 2018 to $14^{\text {th }}$ September 2018.

\section{Inclusion criteria}

- All patients having atonic PPH not responding to medical management.

\section{Exclusion criteria}

- Heavy arterial bleeding requiring surgical exploration

- Cervical cancer

- Uterine distorting pathology

- Suspected uterine rupture

- Infection of genital tract

- History of primary coagulation disorder.

After preliminary assessment with regards to the inclusion and exclusion criteria, informed consent was obtained. Balloon was inserted into the uterine cavity with a sponge holding forceps after introduction of Sim's speculum into the vagina and holding cervical lips with sponge holding forceps. Balloon was inflated with appropriate volume of normal saline $(250-500 \mathrm{ml})$ till bleeding was arrested. During caesarean section the balloon was inserted through the uterine incision (pushing the tip to the fundus and pulling the drainage port through the cervix into the vagina with the help of an assistant and inflated with 10-20 cc NS. First layer of uterine closure was done ensuring not to puncture the balloon and rest inflation done after the uterine incision was closed. Vaginal packing was done. To keep the uterus well contracted and retracted over the balloon, oxytocin infusion $20 \mathrm{U}$ in $500 \mathrm{cc}$ Ringer Lactate was continued for 4-6 hours in the postoperative period. After 24 hours balloon was deflated and removed. Oxytocin infusion was started half an hour before deflation. The balloon was deflated slowly at the rate of $50 \mathrm{ml} / \mathrm{hr}$. It was not removed until next 30 minutes after complete deflation, in case need for re-inflation arose. Oxytocin infusion was continued during deflation. If the patient did not bleed for next 30 minutes, the balloon was removed and finally the vaginal packs were removed. Throughout the procedure, adequate antibiotic coverage was maintained along with vaginal packing, the condition of the patient continuously monitored, specially noting the vital parameters, amount of bleeding, urine output, and any other complications.

\section{Statistical analysis}

The data obtained was subjected to statistical analysis. The data so obtained was compiled systematically. A master table was prepared, and the data was subdivided and distributed meaningfully and presented as individual tables along with graphs. Statistical procedures were carried out in 2 steps:

- Data compilation and presentation

- Statistical analysis was done using statistical package of social science (SPSS Version 20; Chicago Inc., USA). Data comparison was done by applying specific statistical tests to find out the statistical significance of the comparisons. Quantitative variables were compared using mean values and qualitative variables using proportions. Significance level was fixed at $\mathrm{p}<0.05$.

\section{RESULTS}

The present study was conducted in the department of obstetrics and gynaecology, Gandhi Medical College and Associated Sultania Zanana Hospital, Bhopal, Madhya Pradesh, India. The study was done for the duration of 1 year.

Most of the patients belongs to age groups of $<25$ years [59 (52.7\%)] followed by $26-30$ years [32 (28.6\%)] and $31-35$ years $[15(13.4 \%)]$. This may be due to the fact that maximum patients who were admitted for confinement were in this age group. Most of the patients were multipara [67 $(59.8 \%)]$ followed by primipara [39 $(34.8 \%)]$ and grand multipara [6 (5.4\%)]. Though risk of $\mathrm{PPH}$ is more in grand multipara but in this study 
multiparas outnumbered grand multipara which may be due to good family planning service is provided and hence only few grand multipara women delivering.

Table 1: Distribution of patients according to gestational age.

\begin{tabular}{|l|ll|}
\hline Gestational age (week) & Numbers & Percentage \\
\hline$<37$ weeks & 29 & $25.9 \%$ \\
\hline$>37$ weeks & 83 & $74.1 \%$ \\
\hline Total & 112 & $100 \%$ \\
\hline
\end{tabular}

As shown in Table 1, most of the patients [83 (74.1\%)] had gestational age more than 37 weeks and 29 (25.9\%) patients had gestational age less than 37 weeks.

Table 2: Distribution according to different types of balloon devices used to control PPH.

\begin{tabular}{|lll|}
\hline Type of balloon device used & Numbers & Percentage \\
\hline Bakri balloon & 84 & $75.0 \%$ \\
\hline CG balloon & 4 & $3.6 \%$ \\
\hline Condom catheter & 7 & $6.3 \%$ \\
\hline Burke balloon & 17 & $15.2 \%$ \\
\hline Total & 112 & $100.0 \%$ \\
\hline
\end{tabular}

As shown in Table 2, in most of the patients Bakri balloon was used [84 (75.0\%)] followed by Burke balloon $[17(15.2 \%)]$ followed by condom catheter [7 $(6.2 \%)$ ] and CG balloon in $4(3.6 \%)$ patients. Different types of balloon were used according to availability of balloon at the time of management.

Table 3: Distribution of cases according to route of balloon placement.

\begin{tabular}{|lll|}
\hline Route of balloon placement & Numbers & Percentage \\
\hline Transvaginal & 71 & $63.3 \%$ \\
\hline Transabdominal & 41 & $36.7 \%$ \\
\hline Total & 112 & $100.0 \%$ \\
\hline
\end{tabular}

As shown in Table 3, most of the patients [71 (63.3\%)] had trans-vaginal route of balloon placement and 41 (36.7\%) patients underwent trans-abdominal balloon placement. As shown in Table 4, most of the patients, 69 (61.65\%) responded to tamponading within 20 minutes of balloon placement while 9 patients had negative tamponade and continued to bleed.

Table 4: The mean time taken to arrest bleeding after application of balloon tamponade.

\begin{tabular}{|l|l|l|}
\hline Time taken & Numbers & Percentage \\
\hline $1-10$ minutes & 34 & $30.35 \%$ \\
\hline $10-20$ minutes & 69 & $61.65 \%$ \\
\hline $\begin{array}{l}>20 \text { minutes (bleeding } \\
\text { not arrested) }\end{array}$ & 9 & $8.0 \%$ \\
\hline Total & 112 & $100 \%$ \\
\hline
\end{tabular}

Table 5: Results according to type of balloon devices used.

\begin{tabular}{|llll|}
\hline Outcome of PPH & Successful & Unsuccessful & Total \\
\hline Bakri balloon & $81(96.4 \%)$ & $3(3.6 \%)$ & 84 \\
\hline CG balloon & $3(75 \%)$ & $1(25 \%)$ & 4 \\
\hline Condom catheter & $7(100 \%)$ & $0(0.0 \%)$ & 7 \\
\hline Burke balloon & $12(70.6 \%)$ & $5(29.4 \%)$ & 17 \\
\hline Total & $103(92.0 \%)$ & $9(8.0 \%)$ & 112 \\
\hline
\end{tabular}

As shown in Table 5, Bakri balloon tamponade was most commonly used in $84(75.0 \%)$ patients. CG Balloon and condom catheter were used only in $4(3.6 \%)$ and $7(6.3 \%)$ patients respectively. Tamponading was effective and successful in $103(92 \%)$ patients.

Table 6: Distribution of cases according to results of balloon tamponade.

\begin{tabular}{|lll|}
\hline Result & Numbers & Percentage \\
\hline Successful & 103 & $92.0 \%$ \\
\hline Unsuccessful & 09 & $8.0 \%$ \\
\hline Total & 112 & $100 \%$ \\
\hline
\end{tabular}

As shown in Table 6, in most of the patients balloon tamponade was successful in controlling PPH [103 $(92.07 \%)]$ while in $9(8.0 \%)$ patients $\mathrm{PPH}$ was not controlled and they underwent hysterectomy.

\section{DISCUSSION}

Present study was conducted in department of obstetrics and gynecology, Gandhi Medical College and Associated Sultania Zanana Hospital, Bhopal, Madhya Pradesh, India, over a period of one year. 112 patients were included in the study.

In present study maximum patients were of age 37 weeks. Sadiq A et al conducted a similar study and reported the similar finding that the gestation of $55.2 \%$ patients was between 37-40 weeks. ${ }^{4}$ Sudha $R$ et al conducted a prospective observational study and reported that 7 cases i.e. $58.33 \%$ of the 12 cases were term gestations. ${ }^{5}$ Santhanam $\mathrm{R}$ et al also quoted the similar result that $93.44 \%$ of the total patients were in the gestational age $>37$ weeks. $^{6}$

A total $64(57.1 \%)$ women have had normal vaginal delivery and $48(42.9 \%)$ underwent LSCS. Although LSCS is greater risk factor for PPH, higher numbers of PPH cases were seen in the vaginal delivery. This may be due to the fact that $>65 \%$ women admitted in the institute had vaginal delivery making the absolute number greater. Manisha et al, conducted a similar study and reported the similar finding that majority of the cases i.e. 19 out of 25 $(76 \%)$ had spontaneous vaginal delivery and $6(24 \%)$

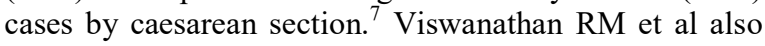
quote the similar result that $50.8 \%$ of the total patients had normal delivery. ${ }^{6}$ 
It was observed that in present study Bakri balloon tamponade was most commonly used in $84(75.0 \%)$ patients. Burke balloon was used in $17(15.2 \%)$ patients. Condom balloon and CG catheter were used only in 7 $(6.3 \%)$ and $4(3.6 \%)$ patients respectively. Different types of balloons were used according to availability of balloon at the time of management. Route of balloon placement was transvaginal in $71(63.39 \%)$ and transabdominal in $41(36.60 \%)$. Transvaginal route $(57.1 \%)$ was used in all patients who delivered vaginally and in 7 patients who underwent LSCS and had PPH postoperatively. One patient had atonic PPH after reposition of uterine inversion and tamponading was done. Yadav S et al, also reported the effectiveness of balloon tamponade in patient with uterine inversion. ${ }^{8}$ In two patients of atonic bleeding B Lynch uterine compressive sutures were applied simultaneously with balloon tamponade. Wai Yoong et al, also reported the successful application of uterine compression suture in association with intrauterine balloon tamponade (uterine sandwitch). ${ }^{9}$ In this study most of the patients $69(61.65 \%)$ responded to tamponading within 20 minutes of balloon placement while 9 patients $(8.0 \%)$ had negative tamponade and continued to bleed.

In this study out of 112 patients, outcome was successful in $103(92.0 \%)$ patients while among $9(8.0 \%)$ it was unsuccessful, and they underwent hysterectomy. Mortality occurred in 10 patients who tided over PPH but died due to other complications. The overall success rate of balloon catheter in present study was $92 \%$ which was comparable with other studies. Goldrath first described the use of Foley's catheter tamponade, successful in 17 out of 20 patients $(85 \%)$. A review of case reports of balloon tamponade in the management of PPH by Georgiou showed that success was obtained in 97/106 $(91.5 \%)$ cases. $^{10}$

\section{CONCLUSION}

PPH is still a leading but preventable cause of maternal morbidity and mortality. In the majority of cases, relatively simple methods are used to avert a disaster, although these are not always employed. Uterine tamponade using intrauterine balloons appears to be an effective tool in the management of $\mathrm{PPH}$.

Funding: No funding sources Conflict of interest: None declared

Ethical approval: The study was approved by the Institutional Ethics Committee

\section{REFERENCES}

1. World Health Organization, World Bank, UNICEF, United Nations Population Fund. Trends in Maternal Mortality: 1990 to 2008. Geneva: World Health Organization, 2010. Available at: http://www.who.int/reproductivehealth/publications/ monitoring. Accessed on 10 January 2020.

2. United Nations Goal 3: Sustainable development knowledge platform 2016. New York: UN; 2015. Available at: http://www.un.org/sustainabledeve lopment/news/communications-material. Accessed on 10 January 2020.

3. Carroli G, Cuesta C, Abalos E, Gulmezoglu AM. Epidemiology of postpartum haemorrhage: a systematic review: Best Pract Resclinobstet Gynaecol. 2008;22(6):999-1012.

4. Munir SI, Sadiq A, Ishtiaq S. Frequency of causes of primary postpartum hemorrhage in a tertiary care hospital. Annal King Edward Medi Univ. 2015;21(1):33.

5. Sudha R, Anjali R. Intrauterine balloon tamponade in the management of severe PPH: Case series from a tertiary care hospital. Inter $\mathrm{J}$ Conte Med Res. 2017;4(1):93-6.

6. Santhanam R, Viswanathan RM, Priya V. Condom tamponade in the management of atonic PPH. Int $\mathrm{J}$ Reprod Contracept Obstet Gynecol. 2018;7(6):227682.

7. Gupta M, Jain M. Role of condom catheter balloon tamponade in management of atonic PPH in cases of failed medical management. Int $\mathrm{J}$ Clin Obstet Gynaecol. 2017;1(2):62-4.

8. Yadav S, Malhotra A. Novel use of balloon tamponade saves a patient with uterine inversion in severe shock. Int $\mathrm{J}$ Reprod Contracept Obstet Gynecol. 2017;6(12):5638-41.

9. Yoong W, Ridout A, Memtsa M, Stavroulis A, ArefAdib M, Ramsay-Marcelle Z, et al. Application of uterine compression suture in association with intrauterine balloon tamponade ('uterine sandwich') for postpartum hemorrhage. Acta Obstet Gynecol Scand. 2012;91(1):147-51.

10. Georgiou C. Balloon tamponade in the management of postpartum haemorrhage: a review. Inter J Obstet Gynaecol. 2009;116(6):748-57.

Cite this article as: Kumar A, Kachchhap K, Shrivastava S. A study of the efficacy and safety of the balloon tamponade in the management of atonic post-partum hemorrhage. Int J Reprod Contracept Obstet Gynecol 2020;9:1576-9. 